O'Connor, during the Peninsular war. Both books, it should be added, are capitally illustrated with plates and plans. Dr. Gordon Stables's volume, telling the story of three boys who sailed in search of fortune, is full of exciting situations and adventures and is likewise well illustrated. It is excellent reading for boys.

Messrs. C. Arthur Pearson, Limited, have sent us the following:-Strange Stories of the Hospitals. By Frank Aubrey. Price 2s. 6d. This little book is published to be sold in aid of the metropolitan hospitals and medical charities. The author has presented it as a free gift to the Council of the Hospital Saturday Fund, who will receive all profits arising from the sale of the book and will apply them to the objects of the fund. This being so we will not attempt to criticise the stories further than to say that they are quite readable and will serve to enliven a spare half hour. The expenses of publication have been borne by Lady Meux and Mr. Frank Isitt to whom as well as the author we offer our thanks for the assistance thus given to that form of charity in which we ourselves take a special interest.

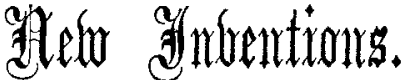

\section{IMPROVEMENTS IN CRUTCHES.}

WE have received from Messrs. Arnold and Sons, of West Smithfield, a pair of crutches of a new design, their distinguishing feature being that the padded leathercovered heads are not fixed immoveably to the uprights, but are capable of a limited rocking motion, so that as the person using them walks along the unavoid. able to-and-fro movement of the crutch does not cause the head to shift its position in the armpits. A uniform pressure under the arm is thereby given and friction against the armpit is reduced to a very small amount. adding to the comfort of the userand diminishing the tendency to wear out the sleeve of the coat or dress. The crutches are strong and quite rigid in respect of affording support to the body, and at the same time the heads possess a certain amount of elasticity and "give" which will be appreciated by users. They have a well. finished appearance,

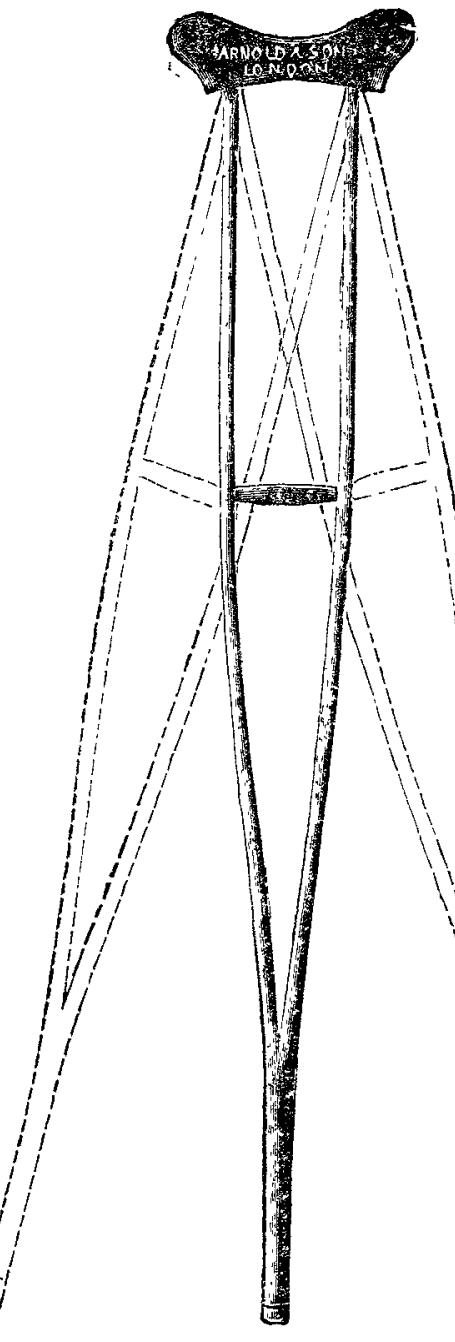
easily be left in the wound. Mr. Charles Stonham has sug gested the use of specially woven ribbon gauze with an edge which cannot fray, and the Galen Manufacturing Company, of Ladywell, London, S.E., have manufactured gauze of a uniform width of 2 in.; this is supplied either plain or medicated with the antiseptics in ordinary use, such as sal alembroth, carbolic acid, and iodoform. From a sample with which we have been supplied we are able to say that this ribbon gauze will prove useful for the purpose for which it is intended; it cannot fray as the threads of the woof do not terminate at the edge of the material. It is packed in bottles in convenient lengths of about 12 in.

\section{NASAL CURETTES.}

THESE instruments, of which an illustration is given, have been designed for the purpose of performing curettement of the nasal mucous membrane. Each curette consists of a bandle and a blade jointed together in such a way as to permit of its being flexed to, and fixed at, any angle that

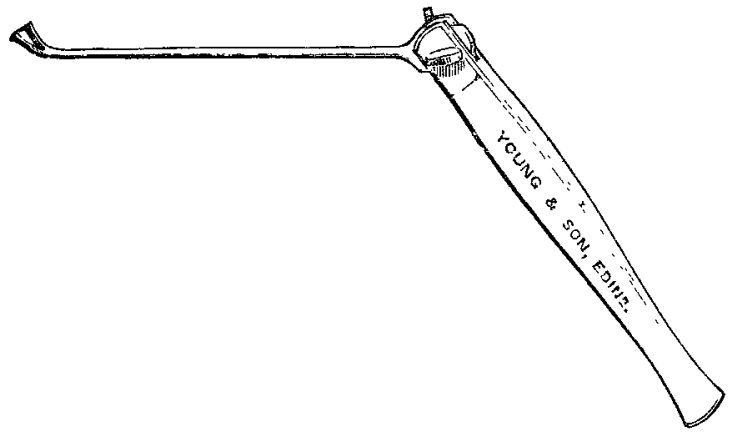

the operator may desire. The curettes, of which there are five in a set, vary according to the size, shape, and angle of their scraping points. They have been made for me by Messrs. Young and Son, Forrest-road, Edinburgh.

Edinburgh. $\quad$ G. HUNTER MaCkenzie, M.D. Edin.

\section{A NEW PARALLEL EXPANDING RECTAL} SPECULUM.

IT is said that the multiplicity of instruments for one use indicates that not one is perfect. If this be so no excuse is needed for invention or improvement. After a fair trial of the instrument represented below-which has been skilfully made by Messrs. Arnold and Sons at my suggestion-I can confidently recommend it. It is simple, effective, and self-retaining. Its open construction affords an extensive field, allowing light in weight, and are extremely simple in construction, having no springs or mechanism liable to become disordered. Messrs. Arnold and Sons state that a pair of these crutches have been recently tested by a cripple who walked 100 miles with them in one week without suffering from soreness or strain or otherwise distressing himself.

\section{MILNE'S RIBBON GAUZE.}

ETERY surgeon must have experienced great difficulty in using strips of gauze for plugging wounds ; the gauze cannot be torn and must be cut to form a strip and then the edges are very prone to fray, so that particles of cotton can very

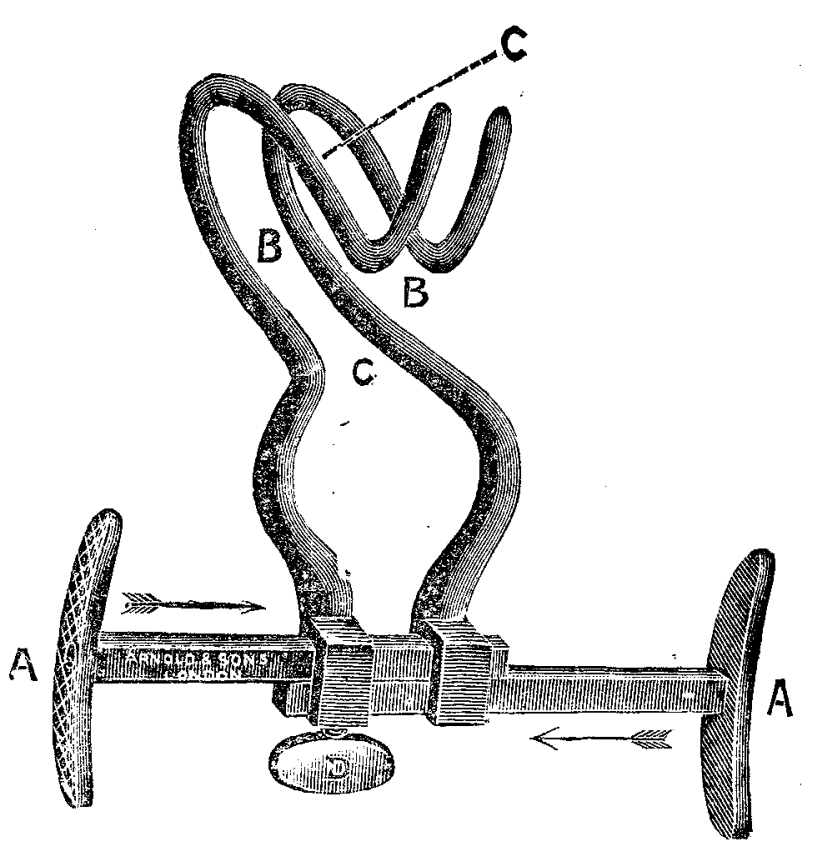

A A handles for use in insertion, $\mathrm{D}$ the binding screw fixing the slide marked by the arrows.

of many manipulations. Thus C C and B B are open spaces. $\mathrm{A}$ and $\mathrm{A}$, or with obdurate sphincters the thumb may be placed in $\mathrm{C}$, and $\mathrm{C}$ and $\mathrm{A}$ approximated. Thus the resistance of the sphincter is met by the intelligent hand and not by a lever or screw. The instrument is shown partly open. To withdraw see that $D$ is not in action and press the blades together.

Finsbury-pavement, E.C. JAMES MACMUNN To open the instrument the hand grasps and approximates 


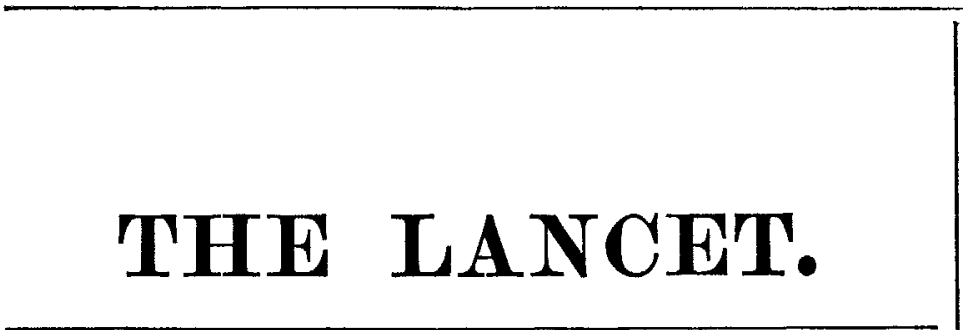

LONDON: SATURDAY, DECEMBER 10, 1898.

WE are disposed, upon consideration of the various penal cases decided upon by the General Medical Council at their recent sitting, to be very proud of our profession. A great deal is heard about any irregularity of conduct in a medical man when it occurs, but that is because the general standard of behaviour is so high that all departures from it excite comment and surprise. Noblesse oblige: the obligations of our high functions are recognised and they are fulfilled. Upon what other view can we explain the fact of the small list even of charges which are brought against members of the profession for professional misconduct and the comparatively light nature of the charges themselves? The public despite the strenuous attempts of a section of the lay press trust their medical men, and they may well be confirmed in their high estimate when they see that of 34,000 men only 5 have been brought under the disciplinary notice of the General Medical Council and that but 2 of these were found to have been unworthy to remain on the Medical Register. We are no apologists for any laxness of professional behaviour, for any falling away from the high standard of service which the best practitioners have set up for their own guidance and which the man whose work lies among the poorest of our inhabitants or in the remotest village of our land often best exemplifies. But the tribunal of the General Medical Council is not a lax one, and when we look at the penal cases recently heard before it we feel almost inclined boastfully to aver that the natural liability of human nature to error is in the medical profession reduced to a minimum. We recommend our readers occasionally to devote a few moments to the consideration of cases which come before the Council and which, of course, represent a larger number of similar cases which evade such publicity. The study of them will help practitioners to avoid those technical offences which are apt to involve a summons to appear before the General Medical Council.

In 2 only of the 5 cases brought under the judicial notice of the Council did the Council proceed to the use of its great and only weapon of punishment-the removal of the offending practitioner from the Medical Register. One of these was the case of John Lloyd Whitmarsh. The Council in his case was spared the trouble and the pain of an investigation of the facts which do not need any repetition here. His conviction at the Central Criminal Court for the murder of ALICE BAYLX being duly reported to the Council its duty, under the 29th clause, was obvious. His removal from the Register purges the profession of one who had brought disgrace on it. The use of medical knowledge to commit illegal and immoral acts is the greatest prostitution of knowledge. The public has great reason to be pleased when this crime is brought to light and when condign punishment falls on the offender, but it cannot be more gratified by such exposure than are the members of the medical profession who feel that the preservation of human life in all its stages is their supreme function. The second and only other case of erasure was that of the name of Mr. Frederick ALFred Frsher, M.R.C.S. Eng., L.S.A. This practitioner was charged with seeking to attract practice by public advertisements in newspapers of his dispensary for "nervous debility" in all the forms which that term suggests. We deeply regret that any registered practitioner should resort to such methods of attracting attention to himself and his remedies. The lesson to be drawn from Mr. FIsHeR's fate is to avoid tampering with the weaknesses and ignorance of human nature and with all forms of practice which involve doing so. We desire to offer to Dr. HUGH WooDs our ccngratulations upon the effective way in which he conducted this very proper prosecution on behalf of the Incorporated Practitioners' Society.

The remaining cases which occupied much of the time of the Council are such as almost necessarily arise out of the system so lately prevalent of employing unqualified assistants and the resolutions of the Council restraining that practice. Three registered medical men found themselres on their defence before the Council for the alleged wrongful use of assistants in practice. They were all subjected to a long process of inquiry. In the end they were all told that the charge against them was not proved. In one case, that of Mr. Chartes ALEXANDER Ducket, the defendant was the qualified assistant of a registered practitioner and had been blamed at two inquests for sending an unqualified practitioner to help him in his principal's practice. In another case, Mr. Frederic Mercer was charged with sending an unqualified assistant in an emergency to a midwifery case, he himself having seen the case both before and after confinement. The third case, and in some sense the most interesting of the group, was that of Dr. JAMES HAVARD JoNES, who stepped into the vacancy occasioned by the resignation of certain medical appointments at mines by Dr. JoHN JoNES of Clydach, Swansea. Dr. Jones resigned after dismissing an. unqualified assistant, Mr. GEorge JENkINs, who had been for almost a generation a continuous element in the medical attendance on the miners of the district. Principals might change, but Mr. GEORGE JENkins remained till the new rules of the General Medical Council came into force, when. Dr. JoHN JoNES, out of proper deference to the Council's authority, resolved absolutely to part company with him. But as a consequence he found himself forced to resign his appointments at the mines. Dr. HAVARD Jones, a stranger in the district of Clydach, found means at once of conciliating the miners and discontinuing the services of $\mathrm{Mr}$. GEORGE Jenkins. He became Mr. Jenkins's tenant, lived in his house, drove his trap, and paid his daughter for board. The evidence of "covering" was certainly weak, for there was no proof that Mr. Jenkins attended any cases with or for his tenant who was ably defended by Mr. Lawson WALTON, Q.C.

The least pleasant but by no means the least useful part of the work of the General Medical Council is that which has reference to the penal cases. We are sure 